\title{
Perancangan Busana Wanita dengan Tren Gaya Hidup "Back to Nature” Menggunakan Pemanfaatan Kain Serat Alam
}

Rima Febriani1, Adinda Caturludysari2, Vira Pritalia3 1,2,3 Department of Craft, Faculty of Creative Industries, Telkom University, Bandung,

Indonesia

\begin{abstract}
Lifestyle trends "Back to Nature" are now widely adopted by people in Indonesia, especially urban residents who register a healthy and practical lifestyle, using nature-based products, for example fashion products. As one of the largest sub-sector of the creative industry in Indonesia, the fashion industry has the potential and great contribution in efforts to meet the basic needs of society which can directly impact the country's economy. Although lifestyle can influence trends in clothing needs, the role of the designer is needed to direct and produce a variety of clothing that is in harmony with lifestyle needs that return to nature.

To overcome this problem, there is an environmentally friendly method that is currently used by various fashion brands in Indonesia and the trend is the use of natural fiber fabrics in the clothing production process. Many local brand designers respond to this lifestyle by creating clothing based on natural fiber that can be used for daily activities.

This study uses a qualitative method with a business opportunity approach. This study presents the background and development of natural fibre fabrics by various fashion brands in Indonesia to become the current trend, especially in the lifestyle of "Back to Nature" for women. The biggest reason is that the adoption of more environmentally friendly methods for the Indonesian fashion industry can provide many broad benefits.
\end{abstract}

Keywords: natural fabric, lifestyle trends, fashion brands, sustainable fashion

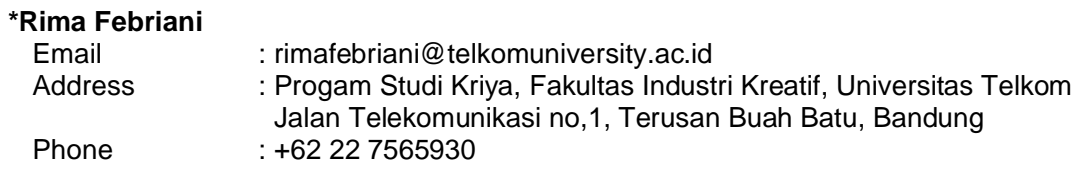




\title{
Perancangan Busana Wanita dengan Tren Gaya Hidup "Back to Nature" Menggunakan Pemanfaatan Kain Serat Alam
}

Rima Febriani, Adinda Caturludysari, Vira Pritalia

\begin{abstract}
PENDAHULUAN
Pola hidup dengan slogan "back to nature" atau kembali ke alam telah menjadi tren masyarakat dunia. Pola hidup ini didasari bahwa segala sesuatu yang berasal dari alam adalah baik dan berguna serta menjamin adanya keseimbangan antara manusia dan alam. Bukti yang mendukung peningkatan lingkungan ekologikal ini adalah meningkatnya individu yang rela membayar lebih untuk produk-produk yang ramah lingkungan [1]. Faktanya tren bisnis dengan produk ramah lingkungan sedang berkembang mulai dari makanan organik, produk pengganti plastik, produk olahan bekas pakai, obat - obatan organik, hingga kosmetik organik. Kini produk busana dengan berbahan ramah lingkungan pun mulai marak bermunculan untuk menjawab kebutuhan konsumen dalam produk sandang. Masyarakat yang telah memiliki kesadaran untuk mempertimbangkan aspek kualitas, keamanan, dan kesehatan, cenderung memiliki ketertarikan terhadap busana yang menggunakan material kain serat alam karena dianggap lebih nyaman, dan "ramah" terhadap tubuh maupun lingkungan. Busana yang lebih "ramah" terhadap tubuh dan lingkungan sering kali berfokus pada clean-cut look dan minimalis [2]. Merespon kebutuhan masyarakat sebagai konsumen, memicu beberapa produsen fashion lokal untuk memproduksi busana menggunakan material kain serat alam. Jika dilihat dari perkembangan dalam teori keilmuan di bidang fashion, fenomena tersebut memicu dinamika teori dalam bidang fashion ramah lingkungan.
\end{abstract}

Pembahasan mengenai konsep ramah lingkungan dalam bidang desain atau fashion salah satunya berada dalam lingkup "sustainable fashion". Berdasarkan hasil penelitian terdahulu [3] sustainable fashion adalah bagian dari tren desain berkelanjutan yang lebih besar dimana produk yang diproduksi dengan pertimbangan lingkungan dan sosial berdampak terhadap seluruh rentang kehidupan total dari produk tersebut termasuk jejak karbon atau carbon footprint. Konsep sustainable fashion dan sustainable design ini lebih komprehensif dibandingkan dengan konsep seperti eco-fashion, eco-design dan green-design dikarenakan bukan hanya menanggapi permasalahan lingkungan yang umumnya terdapat pada proses produksinya saja, tetapi juga pada proses pasca produksi. Sandy Black [4], memaparkan pula bahwa sustainable fashion dapat merefleksikan sifat fashion yang interdisipliner dan dimensi yang kompleks antara etika dan ekologi seperti yang terjadi dalam proses produksi, konsumsi, pemasaran dan representasi fashion yang dinilai sering melibatkan berbagai pertentangan prioritas yang harus direkonsiliasi.

Berbicara tentang menggabungkan kain serat alam tidak akan lengkap tanpa menyebutkan pembuat yang secara etis membuat pakaian menggunakan kain yang indah dan membayar upah yang adil pada pekerja mereka. Beberapa merek dari desainer lokal yang menerapkan kain dengan serat alam ini membuat produk dengan harga yang relatif tinggi, tidak hanya dikarenakan produk tersebut memiliki nilai jual yang tinggi berdasarkan materialnya, namun beberapa desainer pun menerapkan konsep ethical fashion dan juga business ethic.

Berdasarkan fenomena yang ada pada masyarakat Indonesia mengenai kecenderungan mengkonsumsi produk yang berbahan alam tersebut, penelitian ini akan membahas secara deskripsi menggunakan metode kualitatif dengan pendekatan peluang bisnis mengenai beberapa merek lokal yang memanfaatkan kain serat alam pada produk 
utamanya dengan tujuan memenuhi kebutuhan dari masyarakat Indonesia (khususnya wanita) yang menerapkan pola gaya hidup "Back to Nature" dalam kegiatan aktivitas sehari - harinya.

ISI

Gaya hidup menggambarkan keseluruhan diri seseorang yang berinteraksi dengan lingkungannya. Gaya hidup seseorang biasanya tidak permanen dan cepat berubah. Seseorang mungkin dengan cepat mengganti model dan merek pakaiannya karena menyesuaikan dengan perubahan hidupnya. Menurut Kasali [5], para peneliti pasar yang menganut pendekatan gaya hidup cenderung mengklasifikasikan konsumen berdasarkan konsep AIO, yaitu aktivitas (activity), minat (interest) dan opini (opinion) yang dijabarkan sebagai berikut:

a. Activity : aktivitas adalah identifikasi atas apa yang konsumen lakukan, apa yang mereka beli, dan bagaimana mereka menghabiskan waktu mereka.

b. Interest : minat adalah suatu bentuk fokus pada preferensi dan prioritas konsumen. Minat merupakan faktor pribadi konsumen dalam mempengaruhi proses pengambilan keputusan.

c. Opinion : opini merupakan pendapat dari setiap konsumen yang berasal dari pribadi mereka sendiri.

Gaya hidup dengan tema "Back to Nature" adalah gerakan perbaikan mutu kehidupan yang didasari bahwa segala sesuatu yang berasal dari alam adalah baik dan berguna serta menjamin adanya keseimbangan. Sehingga masyarakat yang menjalani gaya hidup "Back to Nature" ini akan selalu memperhatikan segala aspek dalam kesehariannya agar terjaga kesehatan diri dan lingkungan dengan meminimalisir pemakaian kimia dan pemborosan sumber daya. Konsumen yang mempunyai kesadaran tinggi terhadap lingkungan akan memilih produk-produk yang ramah lingkungan walaupun harganya relatif lebih mahal. Selain pangan, bentuk sandang atau pakaian dengan berbahan alam pun kini marak digemari oleh masyarakat Indonesia yang terbiasa mengkonsumsi dan mengadaptasi pola gaya hidup sehat.

Merespon kebutuhan masyarakat sebagai konsumen, industri fashion merupakan sebuah wadah berkreasi bagi para produsen dan pemilik fashion brands untuk menggali kreatifitas dengan nilai - nilai keindahan dari sebuah material yang memiliki unsur karya yang identik. Upaya produsen dalam membentuk produk busana yang ramah lingkungan sudah mulai banyak terlihat dari munculnya beberapa brand yang menggunakan material alam sebagai bahan utama pada produk fashion masa kini. Beberapa fashion brands yang memanfaatkan material alam sebagai produk fashionnya adalah sebagai berikut : 
Tabel 1 Fashion Brands yang memakai bahan serat alam dengan penggayaan "Back To Nature"

\begin{tabular}{cccc}
\hline Bo & Materials & Technique & Price Range \\
\hline Lepas Wear & Cotton, & Linen, \\
Tencel & Loose Cut & $\begin{array}{c}\text { IDR } 300.000- \\
\text { IDR } 800.000\end{array}$ \\
\end{tabular}

Sumber : https://www.instagram.com/lepaswear/

2

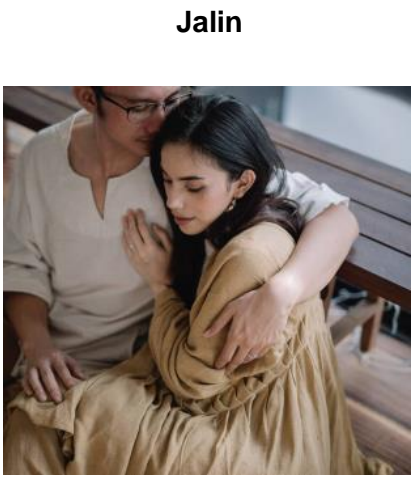

Sumber :

https://www.instagram.com/menjalin/
Cotton, Loose Cut,

Rayon Mix Material

Fiber \& Natural Dye
IDR $500.000-$

IDR 900.000

3

Sukkha Citta

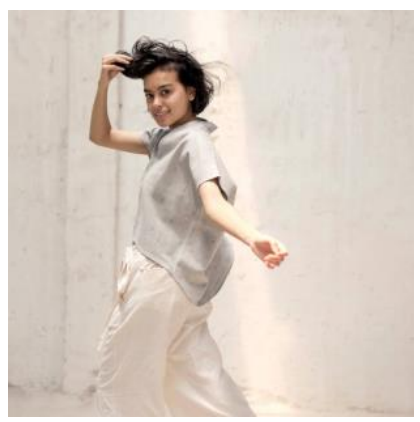

Sumber :

https://www.instagram.com/sukkhacitta/

\section{Cotton, Loose Cut, Tencel, Natural Dye, \\ Linen Batik \\ IDR 950.000 - \\ IDR $\mathbf{3 . 9 0 0 . 0 0 0}$}




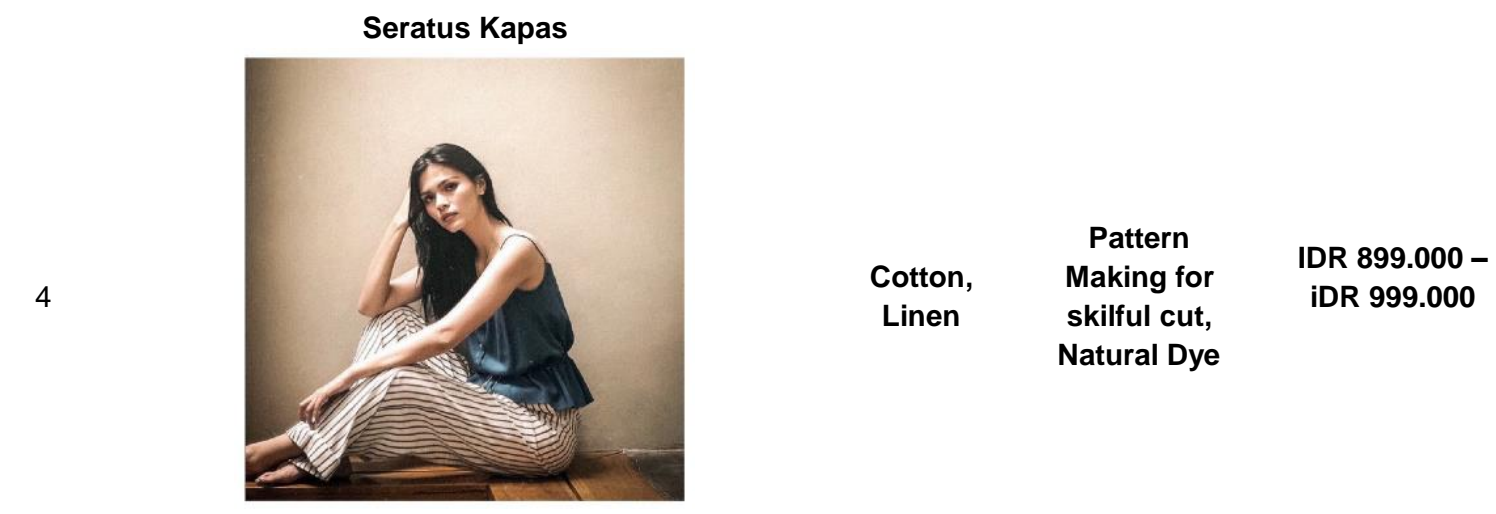

Sumber : https://www.instagram.com/seratuskapas/

\section{SOE Jakarta}

5

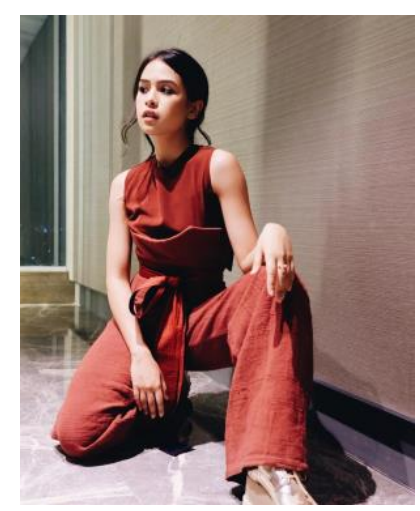

Sumber :

https://www.instagram.com/soe_jakarta/
Cotton

Hand

woven
IDR $950.000-$

IDR 4.050.000

Upaya untuk memenuhi kebutuhan akan gaya hidup turut mempengaruhi tren berbusana. Masyarakat yang telah memiliki kesadaran untuk mempertimbangkan aspek kualitas, keamanan, dan kesehatan, cenderung memiliki ketertarikan terhadap busana yang menggunakan material kain serat alam karena dianggap lebih nyaman dan "ramah" terhadap tubuh maupun lingkungan. Busana yang lebih "ramah" terhadap tubuh dan lingkungan sering kali berfokus pada clean-cut look dan minimalis, namun dari beberapa fashion brands yang sudah disebutkan di atas, dirasa kurang cukup untuk memenuhi kebutuhan lain dari konsumen yang lebih spesifik, salah satunya adalah busana kerja. Busana kerja dengan tetap mengutamakan kesan santai, minimalis dan menggunakan material serat alam, dapat ditujukan bagi konsumen yang memiliki jenis pekerjaan informal. Menurut BeKraf (2016) [6] presentase pekerja informal berdasarkan jenis kelamin yaitu 3.16 juta untuk laki - laki, dan 5.73 juta untuk wanita. Dari data tersebut dapat dilihat bahwa pekerja informal wanita lebih tinggi dibandingkan dengan laki - laki. Dengan tidak terikat oleh perusahaan, lebih memungkinkan bagi konsumen wanita yang menerapkan gaya hidup "Back to Nature" tersebut dalam busana kerja dengan kesan santai, minimalis dan menggunakan material kain serat alam. Berdasarkan fenomena dan masalah yang terjadi, penulis memanfaatkan peluang untuk merancang koleksi busana kerja wanita menggunakan material kain serat alam dengan kesan santai dan minimalis. 
Latar belakang dari penerapan dan pengembangan konsep yang ramah lingkungan bagi produk fashion dikarenakan dirasa adanya potensi secara ekonomi untuk berkembang serta munculnya kesadaran akan pentingnya menjalankan bisnis fashion dengan konsep yang ramah terhadap ekologi atau lingkungan. Konsep pada perancangan karya terbagi menjadi beberapa tahapan, yaitu tahap penentuan material, konsep image board, market research, hingga pembuatan konsep rancangan. Konsep perancangan terinspirasi dari tujuan yang ingin dicapai oleh masyarakat yang menjalankan gaya hidup "Back to Nature", yaitu keseimbangan. Keinginan untuk hidup lebih seimbang masih ada korelasinya dengan budaya Suku Baduy, masyarakat ini memegang teguh aturan dari leluhurnya untuk dapat hidup seimbang, tanpa merusak alam sekitar, dengan cara menolak segala bentuk modernisasi.

Tabel 2 Keterkaitan material serat alam Suku Baduy dengan metode Sustainable Fashion

\begin{tabular}{|c|c|c|}
\hline No & Sustainable Fashion & $\begin{array}{l}\text { Tenun } \\
\text { Baduy }\end{array}$ \\
\hline 1 & $\begin{array}{l}\text { Proses produksi lebih menekankan pada kualitas, craftsmanship, dan tenaga kerja } \\
\text { berpengalaman (Slow fashion movement, 2013). }\end{array}$ & $\checkmark$ \\
\hline 2 & $\begin{array}{l}\text { Proses produksi dikerjakan oleh produsen lokal, guna meminimalisir environmental } \\
\text { footprint saat proses pengiriman material dan produk } \\
\text { (Clark, 2008). }\end{array}$ & $\checkmark$ \\
\hline 3 & $\begin{array}{l}\text { Dikerjakan oleh produsen lokal, meningkatkan transparency antara produsen, retailer, } \\
\text { dan konsumen (Preuit, 2018). }\end{array}$ & $\checkmark$ \\
\hline
\end{tabular}

Berdasarkan konsep perancangan yang diterapkan, aspek dan detail kemudian divisualisasikan melalui image board yang terdiri dari beberapa susunan objek, dan susunan dari masing-masing objek tersebut harus merepresentasikan keseluruhan dari konsep perancangan, sehingga dapat dijadikan acuan dalam perancangan busana. Unsur pada image board seperti, botol skincare organic, line art embroidery, kain linen, tumbuhan kapas, dan warna pada image board ini juga didominasi oleh earth tone colors. Secara garis besar image board ini memberikan kesan natural, kesederhanaan, dan earthy. 


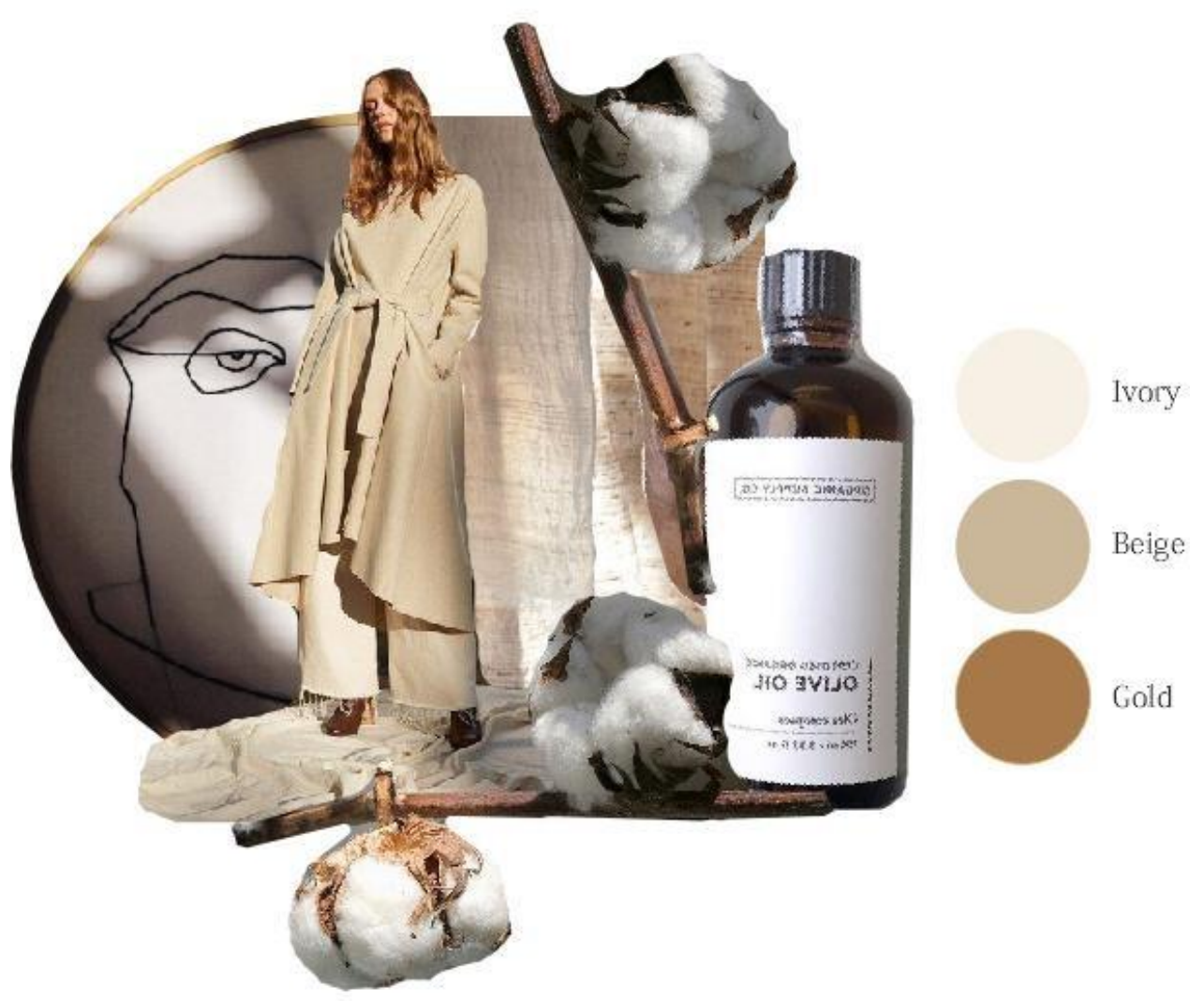

Gambar 1 Imageboard Busana Kerja Wanita dengan Gaya Hidup "Back to Nature"

\section{Customer Segment (Segmentasi Pelanggan)}

\section{A. Geografis}

Berdomisili atau bekerja di kota Bandung, Jakarta, dan Surabaya. Bertempat tinggal di hunian berjenis cluster, town house, atau apartment, dengan lingkungan status sosial menengah atas.

B. Demografis

Wanita berusia 23-30 tahun (generasi milenial), Jenjang pendidikan S1 atau setaranya, bekerja dikegiatan informal (Freelancer, Entertainer, Entrepreneur, dan Industri Kreatif) dengan jumlah pendapatan perbulan setara management level atau status sosial ekonomi, golongan B dan A dengan pendapatan utama perbulan sekitar Rp.4.600.000,- sampai dengan Rp.8.000.000,- keatas.

C. Psikografis

Menjalani tren gaya hidup sehat atau memiliki concern terhadapisu-isu lingkungan, Tidak konsumtif terhadap produk tetapi lebih tidak representatif terhadap harga. Menilai suatu produk berdasarkan kesesuaian value dengan gaya hidup yang dijalani. Cenderung tidak terlalu eksploratif dalam style karena faktor gaya hidup yang dijalani, orang-orang ini membatasi jumlah item busana. Sangat aktif dalam penggunaan sosial media, terutama Instagram. Rutin membagi informasi seputar gaya hidup sehat, review produk, dan review lokasi- lokasi yang sedang dikunjungi.

Sebagai pertimbangan dalam perancangan busana kerja, garis rancang busana mengacu pada clean-cut look dan minimalis. Untuk memberikan keleluasaan dalam kegiatan kerja, siluet yang dipilih adalah A-Line dan $H$-Line, setiap look terdiri dari basic item untuk memberikan kesan tenang, dan formal. Selain itu dari segi bisnis, item tersebut lebih memungkinkan untuk diproduksi dalam skala besar. Material kain yang digunakan 
pada masing - masing look merupakan mixed material antara Tenun Baduy dengan kain linen. Desain yang akan diproduksi adalah sebagai berikut:
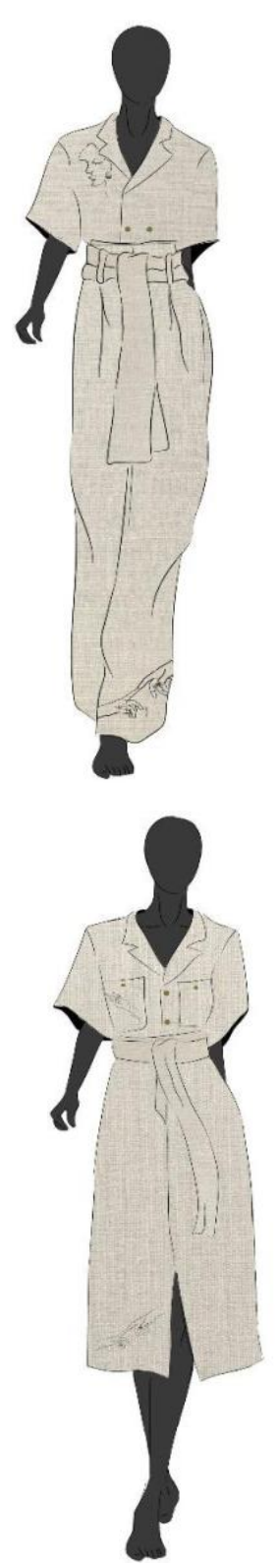
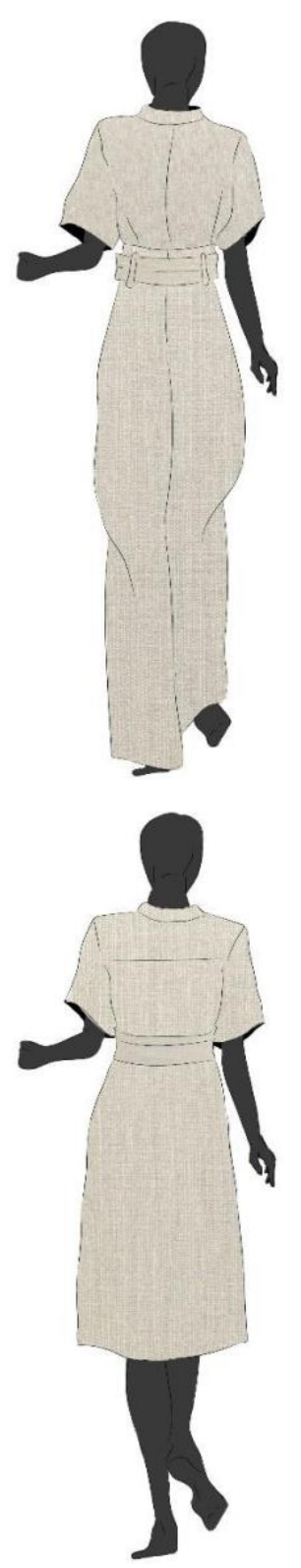
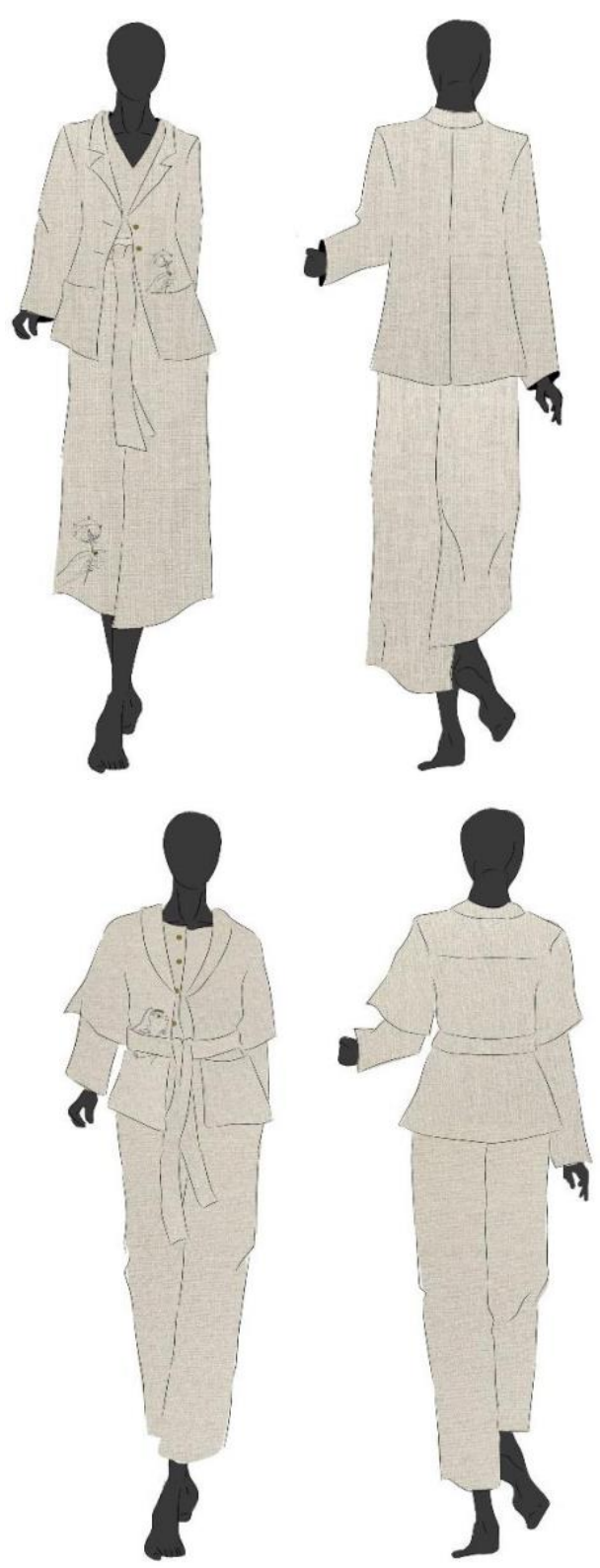

Gambar 2 Desain Perancangan Busana Kerja Wanita dengan Gaya Hidup "Back to Nature"

Selain pemanfaatan material dengan pengolahan desain busana, pemilihan objek dan teknik yang potensial untuk diterapkan sebagai detail pada busana perlu juga diperhatikan. Berdasarkan pertimbangan unsur visual yang sesuai dengan filosofi dari material Tenun Baduy yaitu alami, selaras, dan kesederhanaan serta penempatan pada permukaan kain yang harus tetap memberikan kesan clean-cut look dan minimalis pada busana, maka pemilihan teknik eksplorasi bordir dipilih sebagai teknik yang sesuai. Hal tersebut disertai dengan pertimbangan permilihan warna agar terbentuk kesatuan dari material dan benang yang digunakan. Pemilihan warna pada benang menggunakan warna - warna yang dapat memberikan harmoni dengan warna kain Tenun Baduy dan linen, harmoni pada warna dapat tercipta dari kombinasi warna yang satu dengan yang lainnya. Sedangkan objek yang dapat direpresentasikan terinspirasi dari proses pembuatan Tenun 
Baduy itu sendiri. Seperti yang telah diketahui, proses pembuatan Tenun Baduy hanya boleh dilakukan oleh kaum wanita dari Suku Baduy, proses menenun menggunakan ATBM yang dalam bentuk kerjanya menggunakan tangan atau manual, serta material utama Tenun Baduy adalah benang yang terbuat dari serat kapas. Maka, ketiga unsur tersebut dijadikan sebagai objek visual dalam penambahan detail busana dengan hasil stilasi sebagai berikut:
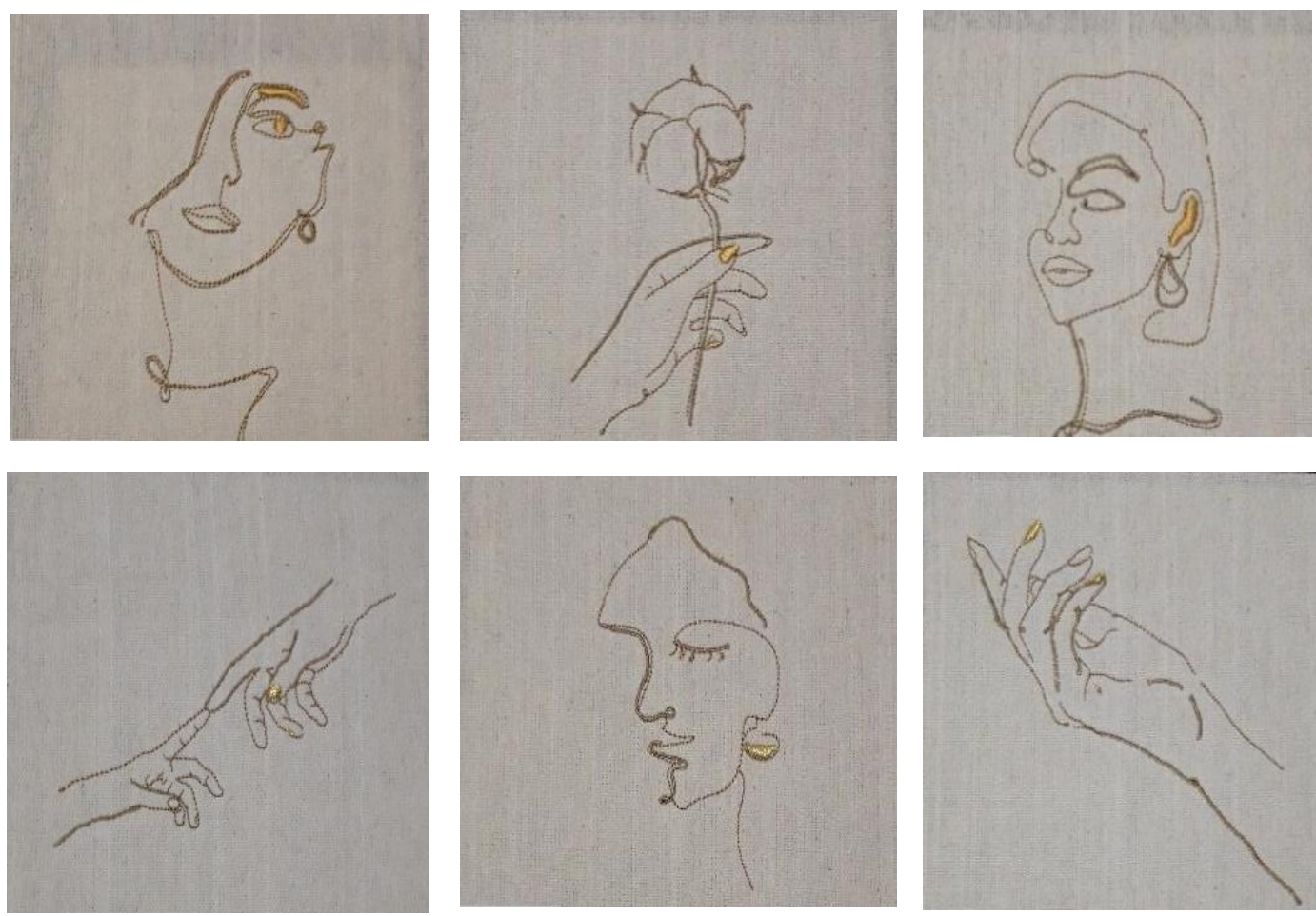

Gambar 3 Stilasi Teknik Bordir sebagai Detail Visual pada Busana Kerja Wanita dengan Gaya Hidup "Back to Nature"

Berdasarkan hasil eksplorasi yang dilakukan didapatkan 6 (enam) bentuk stilasi yang memiliki proporsi yang sesuai, warna terpilih yaitu benang coklat muda dengan aksen gold (metalik), warna metalik dipilih sebagai aksen pendukung, luas area yang dibordir cenderung kecil sehingga porsi warna metalik tidak dominan.

Dari hasil observasi dan ekspremin pada material kain serat alam yang dipakai pada penelitian ini, menghasilkan produk fashion busana kerja untuk wanita dengan tren gaya hidup "Back to Nature" sebagai berikut : 

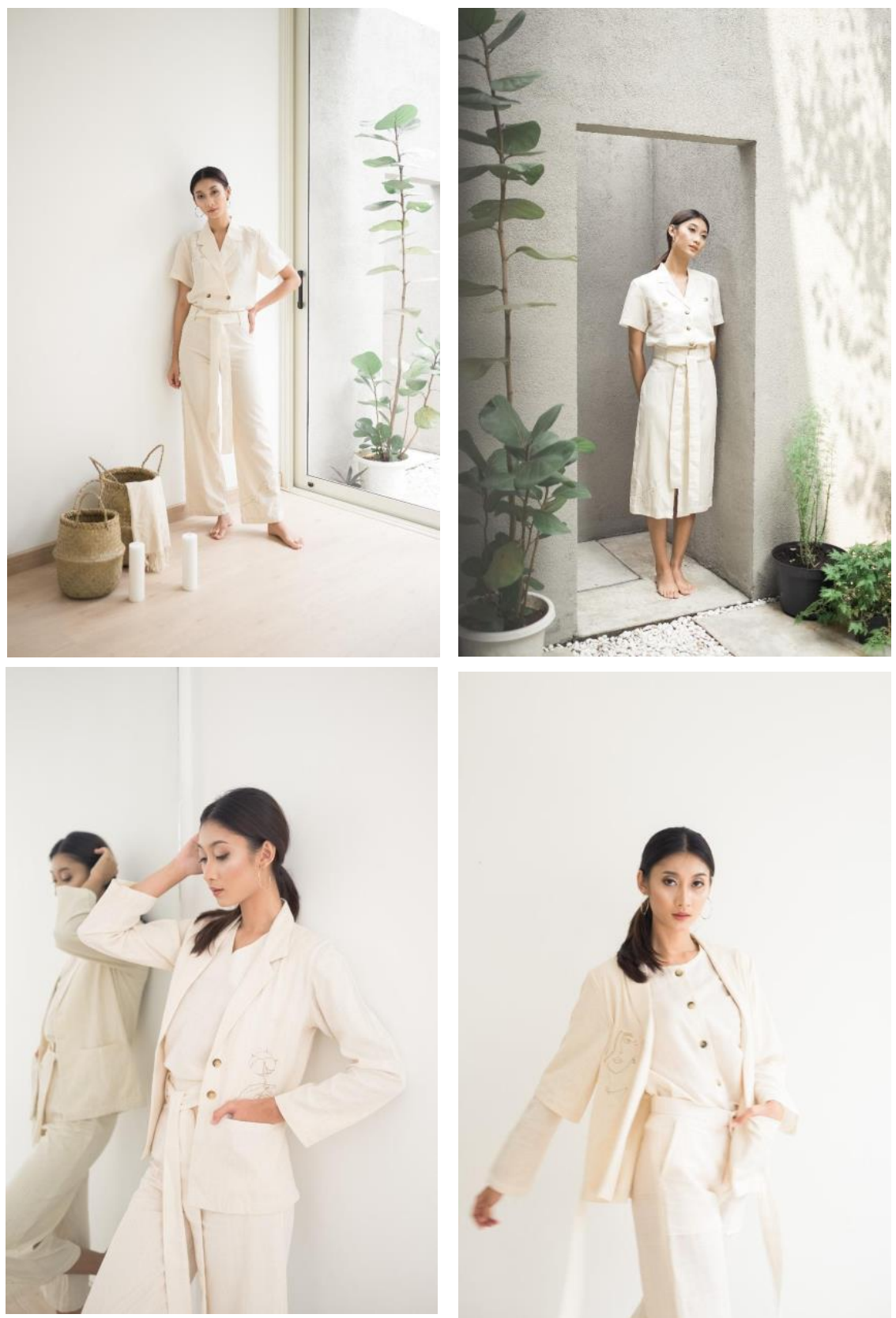

Gambar 4 Visualisasi Produk Busana Kerja Wanita dengan Gaya Hidup "Back to Nature”

Value yang ditawarkan dari produk ini adalah, sebuah fashion brand dengan output produk berupa busana kerja dengan garis rancang yang versatile, menggunakan material kain serat alam dengan memanfaatkan value yang dimiliki dari Tenun Baduy untuk memenuhi kebutuhan masyarakat yang menerapkan gaya hidup "Back to Nature". Memperhatikan etika produksi busana dengan mempertimbangkan jangka waktu pengerjaan, budaya, dan filosofi dari tempat kain yang menjadi material utama pada busana tersebut diproduksi. Selain itu, busana yang diproduksi mengaplikasikan Teknik bordir, dimana produk sejenis dengan material serat alam berfokus pada pewarnaan. Dalam perbandingan besaran harga jual, produk ini memiliki harga jual dikisaran Rp.300.000 - Rp 825.000 yang dinilai dapat bersaing dengan harga di pasar yang sejenis. Adapun bentuk analisis perbandingan dengan produk - produk yang telah disebutkan di atas dapat dirangkum pada tabel dibawah ini : 


\section{Kekuatan / Strength Kelemahan / Weakness}

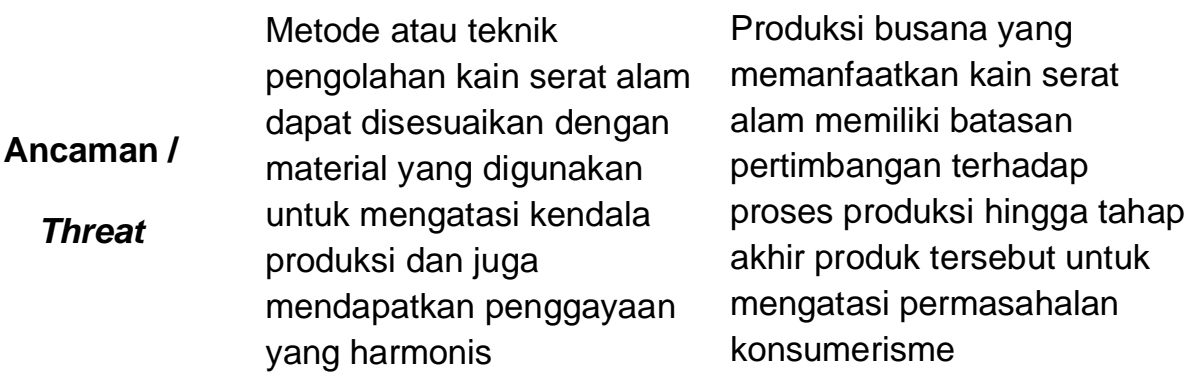

\section{Busana yang} memanfaatkan kain serat

Kesempatan /

Opportunity alam masih terbatas pada ragam busana leisurewear dan belum memfokuskan pada jenis busana yang secara spesifik memenuhi kebutuhan profesi wanita yang sesuai dengan target market

\author{
Perancangan produk fashion \\ yang memanfaatkan kain \\ serat alam masih terbatas \\ bagi beberapa segmentasi \\ pasar saja, dan belum secara \\ luas terpublikasikan
}

\section{KESIMPULAN}

Tren gaya hidup "Back to Nature" dipilih karena memiliki potensi dari segi kebutuhan konsumen untuk menunjang tren gaya hidup sehat yang belum sepenuhnya terjamah oleh sebagian besar produsen fashion. Tren gaya hidup yang mayotitas diterapkan oleh wanita dengan rentang usia $23-30$ tahun ini, merupakan usia produktif wanita untuk bekerja. Namun belum banyak produk fashion yang memenuhi beberapa aspek dengan nilai - nilai tren gaya hidup "Back to Nature" dan menunjang kebutuhan wanita untuk bekerja. Penggunaan material serat alam salah satunya Tenun Baduy dapat meningkatkan ketertarikan konsumen sekaligus menjawab kebutuhan masyarakat yang menerapkan pola gaya hidup "Back to Nature" tersebut khususnya dalam aktivitas kerja.

Setelah melakukan eksplorasi pada permukaan kain, teknik pengolahan material yang dapat menciptakan keserlarasan dan harmoni pada material serat alam adalah teknik bordir karena material yang digunakan sama dengan permukaan kain tersebut yaitu benang. Sedangkan pemilihan warna benang yang digunakan adalah coklat muda guna menghasilkan kesan hangat, santai dan tidak mendominasi tampilan busana.

\section{UCAPAN TERIMAKASIH}

Pada penelitian ini saya ucapkan terima kasih kepada Arini Arumsari, S.Ds, M.Ds yang sudah berbagi ilmu pengetahuan dengan topik yang terkait. Layak untuk disebutkan pula, 
Adinda Caturludysari dan Vira Pritalia yang melakukan penelitian pada tugas akhirnya dengan tema perancangan busana untuk wanita dengan gaya hidup sehat. Dan tentunya tim dari Jurnal Rupa Telkom University, atas kesempatan dan dukungannya agar karya ilmiah kami dapat turut dipublikasikan dengan kualitas yang baik.

\section{DAFTAR PUSTAKA}

[1].Vlosky, Richard P.,Lucie K. Ozanne, \& Renee J. Fontentot. 1999. A Conceptual Model of US Consumer Willingness-to-Pay for Environmentally Certified Wood Products Journal of Consumer Marketing, Vol. 16, No.2, pp.122-136

[2].Brannon, Evelyn L. Lorynn R Divita. 2015. Fashion Forecasting: Studio Instant Access, New York: Bloomsbury Academic.

[3].Arumsari, Arini.2018. Pemanfaatan Pewarna Alam sebagai Trend Baru pada Fashion Brands di Indonesia. Jurnal Rupa.

[4].Black, Sandy. 2012. The Sustainable Fashion Handbook. Thames \& Hudson Ltd. London

[5].Kasali, Rhenald.2005. Membidik Pasar Indonesia : Segmentasi, Targeting, dan Positioning. PT Gramedia Pustaka Utama. Jakarta

[6]. BeKraf. 2016, Jumlah Penduduk Bekerja di Subsektor Ekonomi Kreatif Menurut Kegiatan Formal / Informal. sumber internet http;//data.bekraf.go.id/index.php?r=site\%2Findex. 